\title{
Are clinical outcomes affected by type of plate used for management of mid-shaft clavicle fractures?
}

\author{
Mohammad M. Alzahrani ${ }^{1,2^{*}}$, Adam Cota ${ }^{4}$, Khalid Alkhelaifi ${ }^{1,5}$, Aljarrah Aleidan ${ }^{3}$, Gregory Berry ${ }^{1}$, Rudy Reindl ${ }^{1}$ \\ and Edward Harvey ${ }^{1}$
}

\begin{abstract}
Background: Open reduction and internal fixation (ORIF) using plate osteosynthesis for midshaft clavicle fractures is often complicated by the prominence of the implant due to the subcutaneous position of the clavicle. Reoperation rates for symptomatic clavicle plate removal have been reported to be as high as $53 \%$. We sought to determine to which degree do clinical outcomes (all cause reoperation rate and rate of fracture union) differ between types of clavicle plates.
\end{abstract}

Materials and methods: A retrospective chart review was performed using our hospital database for patients treated with ORIF for mid-shaft clavicle fractures (OTA/AO type 15-B). Implants included in this review were $2.7 \mathrm{~mm}$ reconstruction plates, $3.5 \mathrm{~mm}$ reconstruction plates, $3.5 \mathrm{~mm}$ precontoured clavicle plates and $3.5 \mathrm{~mm}$ locking compression plates. The primary outcome measure was the all cause reoperation rate. Secondary outcomes compared the rate fracture union, documented infection, hardware failures and clinical symptoms at the surgical site among the various plate types. Data was collected and descriptive statistics were analyzed. $p$ values $<0.05$ were considered statistically significant.

Results: A total of 102 midshaft clavicle fractures treated with ORIF were included in this study. The majority of patients were $\leq 50$ years old $(83.3 \%)$ and male (72.5\%). The overall union rate for all plating constructs was $97.1 \%$. We found that age, sex and smoking were not associated with the rate of re-operation. In addition, the fracture classification, type of implant used and number of screws used didn't increase the risk of revision surgery. In addition, more than $50 \%$ of patients complaining of pain at 6 weeks post-operatively required a second surgery for removal of hardware. Moreover, there was no association between age, sex, smoking, fracture classification or plate type and the rate of union. Interestingly, clavicle fractures fixed with $3.5 \mathrm{~mm}$ reconstruction plates were more likely to have hardware failure due to plastic deformation, whereas $2.7 \mathrm{~mm}$ plates were more likely to fail by plate breakage.

Conclusion: Although different types of implants have different biomechanical properties, no difference in reoperation, union and plate removal rates were found between the various plate types. Future studies with a larger sample size are required to further examine these outcomes.

Level of evidence: Level III.

Keywords: Clavicle, Mid-shaft, Fracture, Open reduction internal fixation, Complications, Re-operation, Union

\footnotetext{
*Correspondence: mohammad.alzahrani2@mail.mcgill.ca

1 Division of Orthopaedic Surgery, McGill University, 1650 Cedar Ave,

Montreal, QC H3G 1A4, Canada

Full list of author information is available at the end of the article
} 


\section{Introduction}

Middle third clavicle fractures account for up to $80 \%$ of all clavicle fractures [1-3]. Although historically the majority of these injuries have been treated non-operatively, surgical fixation has been shown to improve clinical outcomes, especially in displaced fracture patterns with significant shortening [3, 4]. Open reduction and internal fixation (ORIF) using plate osteosynthesis for midshaft clavicle fractures is often complicated by the prominence of the surgical implant due to the subcutaneous position of the clavicle. Reoperation rates for symptomatic clavicle plate removal have been reported to be as high as $53 \%$, with female patients being more affected than males [5-7]. We sought to determine to which degree do clinical outcomes differ for plate type following ORIF for midshaft clavicle fractures fixed using superiorly positioned plates by (1) all cause reoperation rate and (2) rate of fracture union.

\section{Materials and methods}

A retrospective chart review was performed using our hospital trauma database for patients treated with open reduction internal fixation for displaced mid-shaft clavicle fractures (OTA/AO type 15-B) between October 2007 and January 2014. Institutional review board approval was granted for the study. Inclusion criteria were patients age greater than 18 years with a minimum of 12 months of clinical follow-up after the index surgery. Surgical indications included acute, mid-shaft clavicle fractures with significant shortening $(>2 \mathrm{~cm})$ or displacement $(>100 \%$ of clavicle width), open fractures, impending skin compromise, associated neurological or vascular injury and polytrauma patients. We excluded any subjects that required operative treatment for a symptomatic nonunion or malunion after failed non-operative treatment, pathological fractures and patients with insufficient radiographs that precluded classification of the fracture pattern. The medical charts and radiographs for the included subjects were reviewed to identify patient demographic information and medical history, mechanism of injury, fracture classification, index surgery characteristics, implant selection and reoperation history. Fractures were classified using the Orthopaedic Trauma Association/Arbeitsgemeinschaft fur Osteosynthesefragen (OTA/AO) criteria [8]. All patients who underwent surgical fixation of their clavicle fracture were treated at a single center. Prophylactic preoperative antibiotics were administrated to the patient before the index surgery was performed $[9,10]$. A standard longitudinal incision was utilized and the supraclavicular nerves were identified and preserved whenever possible. All operative cases received a single, superiorly positioned neutralization plate with interfragmentary lag screw compression when possible. Comminuted fracture patterns were treated using a bridge plate technique to span the area of comminution. The choice of surgical plate was left to the operating surgeon and plate types used included $2.7 \mathrm{~mm}$ calcaneal reconstruction plates, $2.7 \mathrm{~mm}$ reconstruction plates, $3.5 \mathrm{~mm}$ pelvic reconstruction plates, $3.5 \mathrm{~mm}$ precontoured clavicle plates and $3.5 \mathrm{~mm}$ locking compression plates (LCP). All of the implanted plates were manufactured by Synthes, Inc (West Chester, PA). Post-operative management involved sling immobilization for 2 weeks and ongoing clinical and radiographic exams until consolidation of the fracture.

The primary outcome measure was the all cause reoperation rate (including for deep infection, implant failure, non-union and plate prominence). Secondary outcomes included fracture union and documented complications in the study cohort. Data was collected from patient data sheets and patient charts. Data was analyzed using SPSS Version 20 (IBM Corp, Armonk, NY, USA) and descriptive statistics were analyzed. Statistical analysis was performed using Chi square and Fisher Exact test to compare the variables where appropriate. We set our tolerable error for rejecting a true null hypothesis at $0.05 \mathrm{p}$ values $<0.05$ were considered statistically significant.

\section{Results}

A total of 102 patients who underwent primary ORIF for a midshaft clavicle fracture were included in the analysis, these were all the patients in our database who meet the inclusion criteria between October 2007 and January 2014. A summary of patient demographics is presented in Table 1 . The mean age of patients at the time of surgery was $34.9 \pm 12.8$ years, with the majority being $\leq 50$ years old $(83.3 \%)$ and male (72.5\%). Nineteen patients (18.6\%) were smokers (Table 1). The most common mechanism of injury was for bicycle related trauma (31.4\%) followed by fall on an out stretched hand (30.4\%) (Table 1). Only one of the included fractures was an open fracture. Of the fractures included, 33 (32.4\%) were classified as OTA/ AO B1 and 69 (67.6\%) were B2. Mean time to surgery was $8.6 \pm 6.9$ days for the cohort. The most commonly used plate was the $3.5 \mathrm{~mm}$ reconstruction plate $(35.3 \%)$ followed by the $2.7 \mathrm{~mm}$ calcaneal plate (27.5\%) (Table 2). The number of screw holes utilized for each plate construct were eight holes in $41.2 \%$ of the cases and 9 holes in $31.4 \%$. In addition a lag screw technique was used in $47.1 \%$ of the plating constructs (Table 2).

\section{All cause re-operation rate}

Statistically we found that age, sex and smoking were not associated with the re-operation rate. In addition, the OTA/AO fracture classification, time to surgery, type of plate and number of screws used didn't increase the risk of revision surgery. On the other hand, presence 
Table 1 Demographic data of clavicle fracture cohort

\begin{tabular}{lc}
\hline & Number (\%) \\
\hline Sex & \\
Male & $74(72.5 \%)$ \\
Female & $28(27.5 \%)$ \\
Age (years) & \\
$\leq 30$ & $47(46.1 \%)$ \\
$31-50$ & $38(37.7 \%)$ \\
$>50$ & $17(16.7 \%)$ \\
Hand dominance & \\
Right & $51(50 \%)$ \\
Left & $51(50 \%)$ \\
Mechanism & \\
High energy trauma & $24(23.5 \%)$ \\
Low energy trauma & $78(76.5 \%)$ \\
Smoker & \\
Yes & $19(18.6 \%)$ \\
No & $83(81.4 \%)$ \\
Open fracture & \\
Yes & $1(1.0 \%)$ \\
No & $101(99.0 \%)$ \\
OTA classification & \\
B1 & $33(32.4 \%)$ \\
B2 & $69(67.6 \%)$ \\
\hline
\end{tabular}

Table 2 Implants used for open reduction internal fixation of included clavicle fractures

\begin{tabular}{lc}
\hline & Number (\%) \\
\hline Plate used & \\
$2.7 \mathrm{~mm}$ calcaneal & $28(27.5 \%)$ \\
$2.7 \mathrm{~mm}$ reconstruction & $20(19.6 \%)$ \\
$3.5 \mathrm{~mm}$ reconstruction & $36(35.3 \%)$ \\
$3.5 \mathrm{~mm}$ pre-contoured & $8(7.8 \%)$ \\
$3.5 \mathrm{~mm}$ locking compression & $10(9.8 \%)$ \\
Number of plate holes utilized & \\
5 & $2(2.0 \%)$ \\
6 & $9(8.8 \%)$ \\
7 & $14(13.7 \%)$ \\
8 & $42(41.2 \%)$ \\
9 & $32(31.4 \%)$ \\
10 & $3(2.9 \%)$ \\
Lag screw use & \\
Yes & $48(47.1 \%)$ \\
No & $54(52.9 \%)$ \\
\hline
\end{tabular}

of post-operative pain at 6 weeks was associated with a higher rate of re-operation ( $p$ value 0.002 ) as $47.1 \%$ of patients with pain at 6 weeks had a secondary surgery, while only $11.8 \%$ of patients who were pain free required revision surgery (Table 3). The overall reoperation rate was $17.6 \%$, with plate prominence being the most common cause for re-operation (61.1\%) (Table 4).

\section{Union rate and documented complications}

The union rate was $97.1 \%$ for all patients included in the analysis (Table 4). With regards to union rate, there was no association with age, sex, smoking, level of trauma energy, fracture classification, time to surgery or construct characteristics (Table 5). Implant failure was observed in 32 (31.4\%) patients; 17 (16.7\%) of these patients exhibited plate deformation, 8 (7.8\%) had screw pullout and 7 (6.9\%) experienced plate breakage (Table 4). In addition, there were no significant associations between documented complications (infection rate and hardware failure) and patient demographics (age and sex), smoking, mechanism of injury and fracture characteristics (Table 6). We found that clavicle fractures fixed with $3.5 \mathrm{~mm}$ reconstruction plates were more likely to have hardware failure due to plastic deformation, whereas $2.7 \mathrm{~mm}$ constructs where more likely to fail by plate breakage, but these did not reach statistical significance ( $p$ value $=0.173$ and 0.368 ; respectively) (Table 7). Four patients $(3.9 \%)$ in our study developed an infection

Table 3 Outcome and complications of open reduction internal fixation of clavicle fracture cohort

\begin{tabular}{lc}
\hline & Number (\%) \\
\hline Union of fracture & \\
Yes & $99(97.1 \%)$ \\
No & $3(2.9 \%)$ \\
Cause of hardware failure & \\
Plate deformation & $17(16.7 \%)$ \\
Screw pullout & $8(7.8 \%)$ \\
Plate breakage & $7(6.9 \%)$ \\
Re-operation & \\
Yes & $18(17.6 \%)$ \\
No & $84(82.4 \%)$ \\
Reason for reoperation & \\
Prominence & $10(9.8 \%)$ \\
Plate deformation & $3(2.9 \%)$ \\
Plate breakage & $2(2.0 \%)$ \\
Screw pullout & $1(1.0 \%)$ \\
Infection & $1(1.0 \%)$ \\
Infection & \\
Superficial & $3(2.9 \%)$ \\
Deep & $1(1.0 \%)$ \\
None & $98(96.1 \%)$ \\
Post-op symptoms at 6 weeks & \\
None & $17(16.7 \%)$ \\
\hline
\end{tabular}


Table 4 Statistical analysis (Chi square) of re-operation rate in clavicle fracture cohort

\begin{tabular}{|c|c|c|c|}
\hline Patients requiring revision surgery & $n(\%)$ & $\mathrm{d} f$ & $p$ value \\
\hline \multicolumn{4}{|l|}{ Age } \\
\hline$\leq 30$ years $(n=47)$ & $8(17 \%)$ & 2 & 0.06 \\
\hline $31-50$ years $(n=38)$ & $10(26.3 \%)$ & & \\
\hline$>50$ years $(n=17)$ & $0(0 \%)$ & & \\
\hline \multicolumn{4}{|l|}{ Sex } \\
\hline Male $(n=74)$ & $12(16.2 \%)$ & 1 & 0.538 \\
\hline Female $(n=28)$ & $6(21.4 \%)$ & & \\
\hline \multicolumn{4}{|l|}{ Mechanism } \\
\hline High energy trauma $(n=24)$ & $5(20.8 \%)$ & 1 & 0.331 \\
\hline Low energy trauma $(n=78)$ & $11(14.1 \%)$ & & \\
\hline \multicolumn{4}{|l|}{ Smoking } \\
\hline Yes $(n=19)$ & $5(26.3 \%)$ & 1 & 0.272 \\
\hline No $(n=83)$ & $13(15.7 \%)$ & & \\
\hline \multicolumn{4}{|l|}{ Open fracture } \\
\hline Yes $(n=1)$ & $0(0 \%)$ & $N A^{a}$ & 1.0 \\
\hline No $(n=101)$ & $18(17.8 \%)$ & & \\
\hline \multicolumn{4}{|l|}{ OTA classification } \\
\hline $\mathrm{B} 1(n=33)$ & $7(21.2 \%)$ & 1 & 0.514 \\
\hline B2 $(n=69)$ & $11(15.9 \%)$ & & \\
\hline \multicolumn{4}{|l|}{ Plate used } \\
\hline 2.7 mm calcaneal $(n=28)$ & $7(25 \%)$ & 4 & 0.516 \\
\hline $2.7 \mathrm{~mm}$ reconstruction $(n=20)$ & $4(20 \%)$ & & \\
\hline $3.5 \mathrm{~mm}$ reconstruction $(n=36)$ & $6(16.7 \%)$ & & \\
\hline $3.5 \mathrm{~mm}$ pre-contoured $(n=8)$ & 0 & & \\
\hline $3.5 \mathrm{~mm}$ locking compression $(n=10)$ & $1(10 \%)$ & & \\
\hline \multicolumn{4}{|l|}{ Number of plate holes utilized } \\
\hline $5(n=2)$ & $1(50 \%)$ & 5 & 0.250 \\
\hline $6(n=9)$ & $2(22.2 \%)$ & & \\
\hline $7(n=14)$ & $2(14.3 \%)$ & & \\
\hline $8(n=42)$ & $4(11.9 \%)$ & & \\
\hline $9(n=32)$ & $9(28.1 \%)$ & & \\
\hline $10(n=3)$ & $0(0 \%)$ & & \\
\hline \multicolumn{4}{|l|}{ Post-operative symptoms at 6 weeks } \\
\hline Pain, $(n=17)$ & $8(47.1 \%)$ & 3 & 0.002 \\
\hline None $(n=85)$ & $10(11.8 \%)$ & & \\
\hline
\end{tabular}

${ }^{a}$ In these parameters, Fisher's exact test was used for analysis

with only 1 case of deep infection that was managed with a revision surgery.

\section{Discussion}

This study examines the effect of patient demographics, mechanism of injury and plating construct characteristics on the reoperation, union and complication rates after open reduction and internal fixation of mid-shaft clavicle fractures. Our results demonstrated an all cause reoperation rate of $17.6 \%$ with plate prominence being the most common cause of re-operation (61.1\%). This is
Table 5 Statistical analysis (Fisher's exact test) of union rate in clavicle fracture cohort

\begin{tabular}{|c|c|c|}
\hline Union rate & $n(\%)$ & $p$ value \\
\hline \multicolumn{3}{|l|}{ Age } \\
\hline$\leq 30$ years $(n=47)$ & $47(100 \%)$ & \multirow[t]{3}{*}{0.12} \\
\hline $31-50$ years $(n=38)$ & $35(92.1 \%)$ & \\
\hline$>50$ years $(n=17)$ & $17(100 \%)$ & \\
\hline \multicolumn{3}{|l|}{ Sex } \\
\hline Male $(n=74)$ & $73(98.6 \%)$ & \multirow[t]{2}{*}{0.182} \\
\hline Female $(n=28)$ & $26(92.9 \%)$ & \\
\hline \multicolumn{3}{|l|}{ Mechanism } \\
\hline High energy trauma $(n=24)$ & $22(91.7 \%)$ & \multirow[t]{2}{*}{1.0} \\
\hline Low energy trauma $(n=78)$ & $77(98.7)$ & \\
\hline \multicolumn{3}{|l|}{ Smoking } \\
\hline Yes $(n=19)$ & 19 (100\%) & \multirow[t]{2}{*}{1.0} \\
\hline No $(n=83)$ & $80(96.4 \%)$ & \\
\hline \multicolumn{3}{|l|}{ Open fracture } \\
\hline Yes $(n=1)$ & $1(100 \%)$ & \multirow[t]{2}{*}{1.0} \\
\hline No $(n=101)$ & $98(97.0 \%)$ & \\
\hline \multicolumn{3}{|l|}{ OTA classification } \\
\hline $\mathrm{B} 1(n=33)$ & $31(93.9 \%)$ & \multirow[t]{2}{*}{0.244} \\
\hline $\mathrm{B} 2(n=69)$ & $68(98.6 \%)$ & \\
\hline \multicolumn{3}{|l|}{ Plate used } \\
\hline $2.7 \mathrm{~mm}$ calcaneal $(n=28)$ & $27(96.4 \%)$ & \multirow[t]{5}{*}{0.883} \\
\hline $2.7 \mathrm{~mm}$ reconstruction $(n=20)$ & $20(100 \%)$ & \\
\hline $3.5 \mathrm{~mm}$ reconstruction $(n=36)$ & $34(94.4 \%)$ & \\
\hline $3.5 \mathrm{~mm}$ pre-contoured $(n=8)$ & $8(100 \%)$ & \\
\hline 3.5 mm locking compression $(n=10)$ & $10(100 \%)$ & \\
\hline \multicolumn{3}{|l|}{ Number of plate holes utilized } \\
\hline $5(n=2)$ & $2(100 \%)$ & \multirow[t]{6}{*}{0.316} \\
\hline $6(n=9)$ & $8(88.9 \%)$ & \\
\hline $7(n=14)$ & $13(92.9 \%)$ & \\
\hline $8(n=42)$ & $41(97.6 \%)$ & \\
\hline $9(n=32)$ & $32(100 \%)$ & \\
\hline $10(n=3)$ & $3(100 \%)$ & \\
\hline \multicolumn{3}{|l|}{ Post-operative symptoms at 6 weeks } \\
\hline Pain, $(n=17)$ & $16(94.1 \%)$ & \multirow[t]{2}{*}{0.425} \\
\hline None $(n=85)$ & $83(97.6 \%)$ & \\
\hline
\end{tabular}

similar to the results published in a recent study by Leroux et al. [5], examining the incidence and associated risk factors for reoperations after ORIF of midshaft clavicle fractures. The authors found that out of 1350 patients, almost one in four (24.6\%) underwent a subsequent clavicle operation within 2 years of the index surgery with the most common reoperation procedure being performed for isolated implant removal (18.8\%) [5]. In addition, results from the Canadian Orthopaedic Trauma Society (COTS) trial reported that $8 \%$ of clavicle fractures treated with open reduction and internal fixation would require 
Table 6 Statistical analysis (Chi square) of documented complications

\begin{tabular}{|c|c|c|c|c|c|c|}
\hline & Infection rate & $\mathrm{d} f$ & $p$ value & Hardware failure & $\mathrm{d} f$ & $p$ value \\
\hline \multicolumn{7}{|l|}{ Age } \\
\hline$\leq 30$ years $(n=47)$ & $3(6.4 \%)$ & $N A^{a}$ & 0.657 & $13(27.7 \%)$ & 2 & 0.254 \\
\hline $31-50$ years $(n=38)$ & $1(2.6 \%)$ & & & $15(39.5 \%)$ & & \\
\hline$>50$ years $(n=17)$ & 0 & & & $4(23.5 \%)$ & & \\
\hline \multicolumn{7}{|l|}{ Sex } \\
\hline Male $(n=74)$ & $4(5.4 \%)$ & $N A^{a}$ & 0.573 & $22(29.7 \%)$ & 1 & 0.655 \\
\hline Female $(n=28)$ & 0 & & & $10(35.7 \%)$ & & \\
\hline \multicolumn{7}{|l|}{ Mechanism } \\
\hline High energy trauma $(n=24)$ & $1(4.2 \%)$ & $N A^{a}$ & 1.0 & $9(37.5 \%)$ & 1 & 0.743 \\
\hline Low energy trauma $(n=78)$ & $3(3.8 \%)$ & & & $23(29.5 \%)$ & & \\
\hline \multicolumn{7}{|l|}{ Smoking } \\
\hline Yes $(n=19)$ & $1(5.3 \%)$ & $N A^{a}$ & 0.568 & $9(47.4 \%)$ & 1 & 0.173 \\
\hline No $(n=83)$ & $3(3.6 \%)$ & & & $23(27.7 \%)$ & & \\
\hline \multicolumn{7}{|l|}{ Open fracture } \\
\hline Yes $(n=1)$ & 0 & $N A^{a}$ & 1.0 & $1(100 \%)$ & $N A^{a}$ & 0.324 \\
\hline No $(n=101)$ & 4 & & & $31(30.7 \%)$ & & \\
\hline \multicolumn{7}{|l|}{ OTA classification } \\
\hline $\mathrm{B} 1(n=33)$ & 0 & $N A^{a}$ & 0.302 & $9(27.3 \%)$ & 1 & 0.448 \\
\hline B2 $(n=69)$ & $4(58.0 \%)$ & & & 23 (33.3\%) & & \\
\hline
\end{tabular}

a In these parameters, Fisher's exact test was used for analysis

Table 7 Statistical analysis (Fisher's exact test) of hardware failure by type of plate utilized

\begin{tabular}{|c|c|c|c|c|c|c|}
\hline Hardware failure & $\begin{array}{l}2.7 \mathrm{~mm} \text { calcaneal } \\
\text { plate }(n=28)\end{array}$ & $\begin{array}{l}2.7 \mathrm{~mm} \\
\text { reconstruction plate } \\
(n=20)\end{array}$ & $\begin{array}{l}3.5 \mathrm{~mm} \\
\text { reconstruction plate } \\
(n=36)\end{array}$ & $\begin{array}{l}3.5 \mathrm{~mm} \text { pre- } \\
\text { contoured plate } \\
(n=8)\end{array}$ & $\begin{array}{l}3.5 \mathrm{~mm} \text { locking } \\
\text { compression plate } \\
(n=10)\end{array}$ & $p$ value \\
\hline Plastic deformation & $3(10.7 \%)$ & $2(10 \%)$ & $10(27.8 \%)$ & 0 & $2(20 \%)$ & 0.222 \\
\hline Plate breakage & $4(14.3 \%)$ & $1(5 \%)$ & $1(2.8 \%)$ & 0 & $1(10 \%)$ & 0.397 \\
\hline Screw pullout & 0 & $3(15 \%)$ & $5(13.9)$ & 0 & 0 & 0.128 \\
\hline
\end{tabular}

an implant removal procedure within 1 year of the initial procedure [4].

The need for plate removal is often due to plate prominence and poor cosmesis due to the subcutaneous position of the clavicle [6]. We found no statistically significant difference between 2.7 and $3.5 \mathrm{~mm}$ plates on the rate or reoperation nor was there any difference between 2.7 and $3.5 \mathrm{~mm}$ plates on the rate of post-operative pain or numbness 6 weeks post-surgery. Our results are similar to those reported by Galdi et al. [11], who examined whether using a lower profile $2.7 \mathrm{~mm}$ reconstruction plate would lead to better clinical outcomes and lower removal rates when compared to a $3.5 \mathrm{~mm}$ reconstruction plate for ORIF of OTA/AO type B clavicle fractures. The authors reported that using the thinner $2.7 \mathrm{~mm}$ plates provided for higher rates of cosmetic acceptability, but did not demonstrate a statistically significant difference with regards to reoperation rates for plate removal when compared to $3.5 \mathrm{~mm}$ plates [11].
Our reported overall rate of nonunion of $2.9 \%$ is comparable with previously published research. Zlowodzki et al. showed a $2.5 \%$ nonunion rate in a systematic review of 635 clavicle fractures treated operatively [12]. Also in a recent meta-analysis, McKee et al. identified a nonunion rate of $1.4 \%$ of clavicle fracture ORIFs [13]. We did not find an association between nonunion and age, sex, smoking, level of trauma energy, fracture classification, time to surgery or construct characteristics. Leroux et al. found that both female gender and a high comorbidity score (Collapsed Aggregate Diagnosis Group) increased the odds of nonunion in their large cohort [5].

In addition, clavicle fractures fixed with $3.5 \mathrm{~mm}$ reconstruction plates were more likely to exhibit plastic deformation, whereas $2.7 \mathrm{~mm}$ plating constructs utilizing reconstruction plates where more likely to fail by plate breakage. These results are in keeping with previous clinical studies that have demonstrated the susceptibility of 3.5 and $2.7 \mathrm{~mm}$ reconstruction plates to undergo plastic 
deformation when used for open reduction internal fixation of midshaft clavicle fractures [14-17]. Moreover, our infection rate was $3.9 \%$, of which only 1 case required a revision surgery for deep infection. This rate was comparable to available literature where the rate for postoperative infection ranges from 2.6 to $10 \%[5,7]$.

The major limitation of our study is the retrospective design. Despite reporting on a large series of operatively treated clavicle fractures, we were unable to detect a significant difference between plate types with regards to union rates, need for surgical reoperation, incidence of plate removal and the rate of implant failure. Future studies with a larger sample size may detect these differences if present.

This retrospective study demonstrated an overall reoperation rate of $17.6 \%$ for midshaft clavicle fractures treated with open reduction internal fixation utilizing both 2.7 and $3.5 \mathrm{~mm}$ plates. Presence of symptoms (pain and numbness) at the surgical site was associated with an increased risk of re-operation. Although union rate and post-operative complications had no association with the type of plate used, future studies with a larger sample size are required to further examine these outcomes.

\section{Authors' contributions}

MMA, AC, KA: Data collection, analysis and manuscript preparation; AA: Data analysis and manuscript preparation; GB, RR, EJH: Manuscript preparation. All authors have read and approved the final manuscript.

\section{Author details \\ ${ }^{1}$ Division of Orthopaedic Surgery, McGill University, 1650 Cedar Ave, Montreal, QC H3G 1 A4, Canada. ${ }^{2}$ Department of Orthopaedic Surgery, Imam Abdulrah- man Bin Faisal University, Dammam, Saudi Arabia. ${ }^{3}$ Division of Orthopaedic Trauma, Department of Orthopaedic Surgery, Al-Razi Orthopaedic Hospital, Kuwait City, Kuwait. ${ }^{4}$ Rocky Mountain Orthopaedic Associates, Grand Junc- tion, CO, USA. ${ }^{5}$ Department of Orthopedic Surgery, ASPETAR, Orthopaedic and Sports Medicine Hospital, Doha, Qatar.}

\section{Competing interests}

The authors declare that they have no competing interests.

\section{Ethics approval and consent to participate}

For this type of study formal consent is not required. All procedures performed in studies involving human participants were in accordance with the ethical standards of the institutional and/or national research committee and with the 1964 Helsinki declaration and its later amendments or comparable ethical standards. This study was approved by the Institutional Review Board.

\section{Publisher's Note}

Springer Nature remains neutral with regard to jurisdictional claims in published maps and institutional affiliations.

Received: 5 August 2016 Accepted: 14 December 2017

Published online: 15 August 2018

\section{References}

1. Postacchini F, Gumina S, De Santis P, Albo F (2002) Epidemiology of clavicle fractures. J Shoulder Elbow Surg Am Shoulder Elbow Surg [et al] 11(5):452-456
2. van der Meijden OA, Gaskill TR, Millett PJ (2012) Treatment of clavicle fractures: current concepts review. J Shoulder Elbow Surg Am Shoulder Elbow Surg [et al] 21(3):423-429. https://doi.org/10.1016/j.jse.2011.08.053

3. Robinson CM (1998) Fractures of the clavicle in the adult: epidemiology and classification. J Bone Joint Surg Br 80(3):476-484

4. Canadian Orthopaedic Trauma S (2007) Nonoperative treatment compared with plate fixation of displaced midshaft clavicular fractures. A multicenter, randomized clinical trial. J Bone Joint Surg Am 89(1):1-10. https://doi.org/10.2106/jbjs.f.00020

5. Leroux T, Wasserstein D, Henry P, Khoshbin A, Dwyer T, Ogilvie-Harris D, Mahomed N, Veillette C (2014) Rate of and Risk factors for reoperations after open reduction and internal fixation of midshaft clavicle fractures: a population-based study in Ontario, Canada. J Bone Joint Surg Am 96(13):1119-1125. https://doi.org/10.2106/JBJS.M.00607

6. VanBeek C, Boselli KJ, Cadet ER, Ahmad CS, Levine WN (2011) Precontoured plating of clavicle fractures: decreased hardware-related complications? Clin Orthop Relat Res 469(12):3337-3343. https://doi. org/10.1007/s11999-011-1868-0

7. Wijdicks FJ, Van der Meijden OA, Millett PJ, Verleisdonk EJ, Houwert RM (2012) Systematic review of the complications of plate fixation of clavicle fractures. Arch Orthop Trauma Surg 132(5):617-625. https://doi. org/10.1007/s00402-011-1456-5

8. Marsh JL, Slongo TF, Agel J, Broderick JS, Creevey W, DeCoster TA, Prokuski L, Sirkin MS, Ziran B, Henley B, Audige L (2007) Fracture and dislocation classification compendium - 2007: orthopaedic Trauma Association classification, database and outcomes committee. J Orthop Trauma 21(10 Suppl):S1-133

9. Mangram AJ (2001) A brief overview of the 1999 CDC guideline for the prevention of surgical site infection. Centers for disease control and prevention. J Chemother 13(1):35-39. https://doi.org/10.1179/joc.2001.13. supplement-2.35

10. Yeap JS, Lim JW, Vergis M, Au Yeung PS, Chiu CK, Singh H (2006) Prophylactic antibiotics in orthopaedic surgery: guidelines and practice. Med J Malaysia 61(2):181-188

11. Galdi B, Yoon RS, Choung EW, Reilly MC, Sirkin M, Smith WR, Liporace FA (2013) Anteroinferior 2.7- $\mathrm{mm}$ versus 3.5- $\mathrm{mm}$ plating for AO/OTA type B clavicle fractures: a comparative cohort clinical outcomes study. J Orthop Trauma 27:121-125. https://doi.org/10.1097/BOT.0b013e3182693f32

12. Zlowodzki M, Zelle BA, Cole PA, Jeray K, McKee MD, Evidence-Based Orthopaedic Trauma Working G (2005) Treatment of acute midshaft clavicle fractures: systematic review of 2144 fractures: on behalf of the Evidence-Based Orthopaedic Trauma Working Group. J Orthop Trauma 19(7):504-507

13. McKee RC, Whelan DB, Schemitsch EH, McKee MD (2012) Operative versus nonoperative care of displaced midshaft clavicular fractures: a metaanalysis of randomized clinical trials. J Bone Joint Surg Am 94(8):675-684. https://doi.org/10.2106/JBJS.J.01364

14. Collinge C, Devinney S, Herscovici D, DiPasquale T, Sanders R (2006) Anterior-inferior plate fixation of middle-third fractures and nonunions of the clavicle. J Orthop Trauma 20:680-686. https://doi.org/10.1097/01. bot.0000249434.57571.29

15. Drosdowech DS, Manwell SEE, Ferreira LM, Goel DP, Faber KJ, Johnson JA (2011) Biomechanical analysis of fixation of middle third fractures of the clavicle. J Orthop Trauma 25:39-43. https://doi.org/10.1097/BOT.0b013 e3181d8893a

16. Eden L, Doht S, Frey SP, Ziegler D, Stoyhe J, Fehske K, Blunk T, Meffert RH (2012) Biomechanical comparison of the locking compression superior anterior clavicle plate with seven and ten hole reconstruction plates in midshaft clavicle fracture stabilisation. Int Orthop 36:2537-2543. https:// doi.org/10.1007/s00264-012-1671-x

17. Gilde AK, Jones CB, Sietsema DL, Hoffmann MF (2014) Does plate type influence the clinical outcomes and implant removal in midclavicular fractures fixed with 2.7-mm anteroinferior plates? A retrospective cohort study. J Orthop Surg Res 9(1):1-7. https://doi.org/10.1186/s1301 8-014-0055-x 